\title{
Early and Late Complications Following Dynamic Stereotactic Radiosurgery and Fractionated Stereotactic Radiotherapy
}

\author{
Michael R. McKenzie, Luis Souhami, Jean-Louis Caron, André Olivier, \\ Jean-Guy Villemure and Ervin B. Podgorsak
}

\begin{abstract}
Between December 1986 and June 1990, 112 patients (116 lesions), underwent treatment with dynamic stereotactic radiosurgery at McGill University. Of the treated lesions, 59 were arteriovenous malformations and 53 were a variety of other neoplastic or non-neoplastic conditions. In 86 lesions, the treatment was delivered in a single fraction and the treatment of the remaining 30 lesions was fractionated. Complications attributed to treatment developed in seven of the 112 patients $(6.3 \%)$. No relationship was found between complications and prescribed dose, fractionation, collimator diameter, type and anatomical region of the lesion that was treated, or previous irradiation. Although extensive clinical experience will be necessary to determine optimal total doses, the potential role of fractionated treatment, and the tolerance of critical structures to radiosurgery, the relatively low incidence of complications in our series allows us to conclude that radiosurgery is well tolerated by the vast majority of patients.
\end{abstract}

RÉSUMÉ: Complications précoces et tardives de la radiochirurgie stéréotaxique dynamique et de la radiothérapie stéréotaxique fractionnée. Entre décembre 1986 et juin 1990, 112 patients (116 lésions) ont été traités par radiochirurgie stéréotaxique dynamique à l'Université McGill. 59 des lésions traitées étaient des malformations artério-véneuses et 53 étaient d'autres lésions néoplasiques ou non néoplasiques variées. Pour 86 lésions, le traitement a été délivré en une seule fraction et il a été fractionné pour les 30 autres lésions. Des complications attribuées au traitement sont survenues chez 7 des 112 patients $(6.3 \%)$. Il n'existait pas de relation entre les complications et la dose prescrite, le fractionnement, le diamètre du collimateur, le type et le site anatomique de la lésion traitée ou une irradiation antérieure. Même si une expérience clinique considérable sera nécessaire pour déterminer les doses totales optimales, le rôle potentiel du traitement fractionné et la tolérance à la radiochirurgie de structures critiques, l'incidence relativement basse de complications dans nos séries nous permet de conclude que la radiochirurgie esı bien tolérée par la grande majorité des patients.

Can.J. Neurol. Sci. 1993; 20:279-285

The term radiosurgery has been used to describe a variety of techniques which accurately deliver high single doses of radiation to stereotactically defined intracranial targets in such a way that the dose fall-off outside the targeted volume is very sharp. Since Leksell pioneered the use of these techniques in the $1950 \mathrm{~s}^{1,2}$ and developed the gamma unit in the mid-1960s, ${ }^{3}$ hundreds of patients have been treated with radiosurgery in Stockholm. ${ }^{4}$ Although the first patients were treated with protons in Uppsala, ${ }^{2}$ Boston $^{5}$ and Berkeley ${ }^{6}$ in the 1950s, it was not until the 1980 s that the excellent results of radiosurgical treatment of arteriovenous malformations (AVMs) ${ }^{7.8}$ and acoustic schwannomas $^{9}$ and the potential benefit of applying these techniques to the management of other lesions led to the development of other radiosurgical techniques. These are based primarily on the gamma unit ${ }^{10,11}$ and isocentric linear accelerators (linacs) which are in general clinical use. ${ }^{12-18}$ Since radiosurgical facilities are proliferating rapidly in North America and the number of radiosurgically treated patients is increasing, ${ }^{19}$ it is of great importance that the risk of significant adverse effects of radiosurgery be fully studied, defined and understood.

In conventional external beam radiotherapy, brain tolerance is related to the volume of tissue irradiated, the total dose administered, the size of dose fractions, and the total time over which the irradiation is delivered..$^{20}$ Despite the very small volumes that are treated in radiosurgery, the single high dose fractions that are usually administered have been of concern to some radiation oncologists. Nevertheless, significant acute and late effects of radiosurgery have been uncommon. ${ }^{21-24}$ The relationships between the risk of these effects and factors, such as the prescribed dose, targeted volume, location of this volume

From the Department of Oncology (Division of Radiation Oncology) (M.R.M., L.S., E.B.P.), and the Department of Neurosurgery (J-L.C., A.O.. J-G.V.), McGill University, Montréal

Received January 18, 1993. Accepted in final form April 19, 1993

Reprint requests to: Dr. Luis Souhami, Department of Radiation Oncology, Montréal General Hospital, 1650 Cedar Avenue, Montréal, Québec, Canada H3G 1 A4 
relative to critical structures, any previous irradiation, and particular patient characteristics, have been difficult to elucidate.

The aim of this study was to evaluate the first 112 patients who had been treated with linac-based radiosurgery (single treatment) or stereotactic radiotherapy (fractionated treatment) in our center to determine the overall incidence of complications and to ascertain whether or not any relationship between the rate of complications and any of the above factors could be established.

\section{Materials and Methods}

Between December 1986 and June 1990, 112 patients (62 females and 50 males, ranging in age from 5 to 59 years, median 35 years) were treated with dynamic stereotactic radiosurgery at McGill University. The technical details of our radiosurgical technique based on a $10 \mathrm{MV}$ isocentric linac were described elsewhere. ${ }^{18}$ One hundred-and-nine patients had radiosurgical treatment to only one lesion, while two patients had treatment to two separate cerebral metastatic lesions and one other patient had treatment to each of three feeding vessels of a large right frontoparietal AVM. A listing of the 116 lesions treated is given in Table 1.

Table 1. Lesions Treated Using Dynamic Stereotactic Radiosurgery and Fractionated Stereotactic Radiotherapy

$\begin{array}{lr}\text { Arteriovenous malformation } & 59 \\ \text { Cavernous angioma } & 11 \\ \text { Brain metastasis } & 13 \\ \text { Glioma } & 11 \\ \text { Meningioma } & 4 \\ \text { Acoustic schwannoma } & 3 \\ \text { Craniopharyngioma } & 3 \\ \text { Pineal tumour } & 3 \\ \text { Chordoma } & 2 \\ \text { Pituitary adenoma } & 2 \\ \text { Trigeminal neurinoma } & 2 \\ \text { Cerebellar hemangioblastoma } & 1 \\ \text { Seizure disorder } & 1 \\ \text { Trigeminal neuralgia } & 1\end{array}$

The majority of patients had no previous cranial radiotherapy, but eleven patients, nine with brain metastases and two with high grade astrocytomas, had had previous conventional external beam radiotherapy 0 to 84 months (median 6 months) prior to radiosurgery ( 10 patients) or stereotactic radiotherapy (one patient). Nine of these 11 patients had treatment to the whole brain with total dose ranging from 18 to $50 \mathrm{~Gy}$ (median $30 \mathrm{~Gy}$ ). Of these nine patients, one had a boost to a portion of the treated volume to a dose of $15 \mathrm{~Gy}$ (total dose $60 \mathrm{~Gy}$ ), and two other patients had partial brain treatments for disease recurrent following whole brain irradiation to a further dose of $25 \mathrm{~Gy}$ (total dose $45 \mathrm{~Gy}$ ). One of the 11 patients was treated with a large field to the base of the tongue which included the base of the skull to a dose of $60 \mathrm{~Gy}$. One patient was treated with craniospinal irradiation to a dose of $36 \mathrm{~Gy}$ to the whole brain, with radiosurgery administered as a boost to the pineal region.

In preparation for radiosurgery, all patients were planned using stereotactic target localization with angiography, computerized tomography (CT) or magnetic resonance imaging (MRI).
In all 112 patients, the target volume was assumed to be spherical and therefore only one isocenter was used for the radiosurgical treatment of a given volume. The maximum (100\%) in the radiosurgical dose distribution occurs at the treatment isocenter and the $90 \%$ and $80 \%$ isodoses surfaces are spherical with a diameter depending on the treatment collimator used. The lower level isodose surfaces, such as $50 \%$ and $20 \%$, are no longer spherical and exhibit shapes peculiar to the dynamic rotation technique. The treatment dose was prescribed to the $90 \%$ isodose surface in 73 lesions; dose prescription was at the target center $(100 \%)$ in 42 lesions and at the $85 \%$ isodose surface in one. In all patients, treatment was planned such that the $90 \%$ isodose surface covered the maximum diameter of the lesion on the localization images, resulting in the inclusion of minimal amounts of normal brain and other tissue in the high dose volume. ${ }^{25-27}$

In 82 patients, radiosurgical treatment was administered in a single session. In these patients, the dose administered to the $90 \%$ isodose surface ranged from 15 to $50 \mathrm{~Gy}$ (median 38.25 Gy) and the collimator diameter ranged from 5 to $30 \mathrm{~mm}$ (median $11.25 \mathrm{~mm}$ ). The treatment policy was to treat vascular lesions with a single session. Initially the prescribed dose was $50 \mathrm{~Gy}$ and later on it was dropped to $25 \mathrm{~Gy}$. Isolated metastatic tumors were also treated with a single session but with a dose between $15 \mathrm{~Gy}$ and $25 \mathrm{~Gy}$ depending on tumour size and location. Figure 1 is a scattergram of dose vs. collimator diameter for the 82 patients ( 86 lesions) in whom the treatment was administered in a single session.

In the remaining 30 patients, the treatment course was administered in several sessions or fractions using radiosurgical techniques and immobilization by a halo frame. Details of the fractionated stereotactic technique were described elsewhere. ${ }^{27-28}$ The fractionated treatment was introduced in an attempt to improve the therapeutic ratio by exploring the known differences in the response to fractionated irradiation between tumor and normal tissue. In most patients, the fractionated treatment was prescribed for primary lesions larger than $25 \mathrm{~mm}$ in diameter, in particular for lesions located in critical brain structures. Typical fractionated regimen consisted of six treatments of $7 \mathrm{~Gy}$

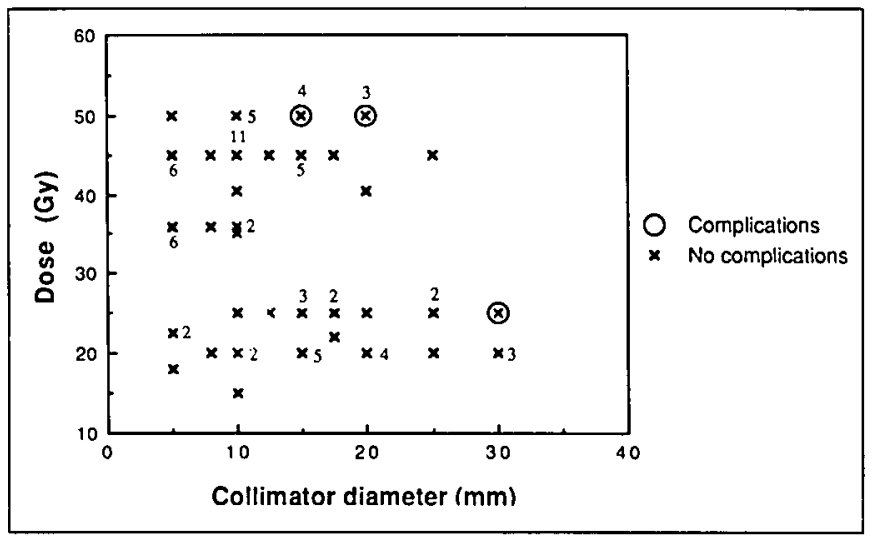

Figure I-Scattergram of cone diameter vs. dose at the $90 \%$ isodose surface for single fraction treatments for 82 patients (86 lesions) with and without intermediate or late brain tissue complications. Numerals indicate the number of superimposed points for patients without complications; each open circle represents one of three patients with complications. 
every second day. Some deviations from this regimen occurred as a result of patients' age and disease histology. In 25 patients, six fractions of 6.3 to $7.5 \mathrm{~Gy}$ were administered on alternate days over a two week period; in the remaining five patients a total dose of 50,27, 40,21, and $32.5 \mathrm{~Gy}$ was administered in two, two, ten, seven, and five sessions, respectively. Figure 2 is a scattergram of dose vs. collimator diameter in the 30 patients in whom the treatment course was administered in multiple sessions. In these patients, the total dose administered to the $90 \%$ isodose surface ranged from 21 to $50 \mathrm{~Gy}$ (median $42 \mathrm{~Gy}$ ) and the collimator diameter ranged from 10 to $35 \mathrm{~mm}$ (median $20 \mathrm{~mm}$ ).

Follow-up ranged from 11 to 53 months (median 29 months). The clinical and treatment records of all patients were reviewed to determine whether or not early or late adverse effects attributable to treatment had occurred. For purposes of analysis, the prescribed doses for the 82 patients treated with a single session were placed into three groups: below $25 \mathrm{~Gy}$, between 25 Gy and $40 \mathrm{~Gy}$, and above $40 \mathrm{~Gy}$. The doses for the 30 patients treated with fractionated therapy also were placed into three groups, in the following ranges: below $35 \mathrm{~Gy}$, between $35 \mathrm{~Gy}$ and $42 \mathrm{~Gy}$, and above $42 \mathrm{~Gy}$. For all patients, collimator diameter was grouped as below $12.5 \mathrm{~mm}$, between $12.5 \mathrm{~mm}$ and 25 $\mathrm{mm}$, or above $25 \mathrm{~mm}$. The lesions were placed in one of two groups: vascular (AVM or cavernous angioma) or non-vascular (benign tumours, malignant tumours, or miscellaneous disorders). The treated region of the brain was classified according to whether the lesion was in or immediately adjacent to the telencephalon (Group 1), diencephalon (Group 2), or mesencephalon, metencephalon, and myelencephalon (Group 3). Groupings of treated lesion types and anatomical regions are given in Table 2. Complications were designated as early if they occurred within 6 weeks of treatment; all other complications were designated as late. In efforts to relate dose, collimator cone size, the presence of previous irradiation, and the type of lesion and region of the brain that was treated to the incidence of complications involving brain parenchyma, statistical comparisons were performed using a $\chi^{2}$ test. Where appropriate (for lesion type only) a correction for continuity was applied.

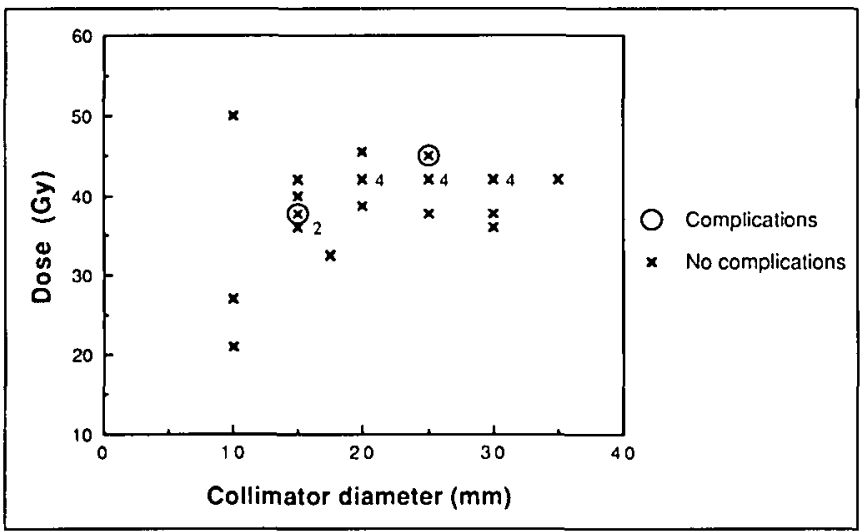

Figure 2 - Scattergram of cone diameter vs. dose at the $90 \%$ isodose surface for multiple fraction treatments for 30 patients with and without intermediate or late brain tissue complications. Numerals indicate the number of superimposed poims for patients without complications; each open circle represents one of two patients with complications.

\section{REsuLts}

Complications attributable to treatment occurred in seven of 112 patients $(6.3 \%)$ and in seven of 116 lesions treated $(6.0 \%)$. None of the patients developed alopecia. Table 3 gives treatment data and summarizes the clinical outcome for the seven patients who developed complications.

Early complications developed in only one patient. He (Patient 1 in Table 3) was treated for a left occipital AVM, and within two to three hours developed a headache accompanied by a right homonymous hemianopsia. A subsequent CT scan of the head revealed no evidence of hemorrhage, and, within six to eight hours of their development, his symptoms resolved completely. The patient developed no further complications and remains well. Follow-up angiogram at one and 2 years posttreatment shows no change in the AVM.

One of the three patients treated for acoustic schwannoma developed complications. He (Patient 2) had had a previous subtotal excision of his tumour but, three years later, developed radiological evidence of local progression of the lesion and was treated with radiosurgery. Two months later, he developed worsening of an ipsilateral partial facial nerve palsy. At seven months following treatment, the facial nerve had recovered its pre-treatment function and a CT scan of the head revealed a slight reduction in the size of the lesion.

Five patients developed intermediate or late adverse effects involving brain tissue. Patient 3 was treated for a cavernous angioma of the left thalamus abutting the internal capsule presenting with a subarachnoid hemorrhage which left him with a residual right hemiparesis. Twenty-one months following treatment, he developed worsening of his hemiparesis and a right homonymous hemianopsia, both of which were progressive. Successive imaging of the brain with MRI and CT revealed extensive edema of the left thalamus and cerebral peduncle. Although his clinical deficits stabilized seven months later, he died of a massive left thalamic bleed at 35 months after therapy. An autopsy revealed that, in addition to a bleed, there were foci of sclerosis of small vessels and deposition of an extracellular amorphous proteinaceous material in the temporal horn, superior and medial to the most lateral portion of the hemorrhage. Although it was felt that the latter could be compatible with radiation necrosis, it was also felt that this change was non-specific in nature, and could be related to the hemorrhage itself.

Patient 4 was treated for a right parietal AVM. Ten months later, he developed progressive left hemiparesis, with CT

Table 2. Lesions Types and Anatomical Regions* for Patients With and Without Brain Parenchymal Complications

\begin{tabular}{lccccc}
\hline & \multicolumn{2}{c}{ No Complications } & & \multicolumn{2}{c}{ Complications } \\
\cline { 5 - 6 } \cline { 5 - 6 } & Single & Fractionated & & Single & Fractionated \\
\hline $\begin{array}{l}\text { Lesion Type } \\
\quad \text { Vascular }\end{array}$ & 66 & 2 & & \\
$\quad$ Other & 17 & 26 & 1 & 1 \\
Anatomical Region* & & & & \\
1 & 47 & 6 & 2 & 0 \\
2 & 21 & 11 & 1 & 2 \\
3 & 15 & 11 & 0 & 0
\end{tabular}

*Anatomical regions: 1- Telencephalon; 2- Diencephalon; 3- Mesencephalon, Metencephalon, Myelencephaton. 
Table 3. Complications of Dynamic Stereotactic Radiosurgery and Fractionated Stereotactic Radiotherapy

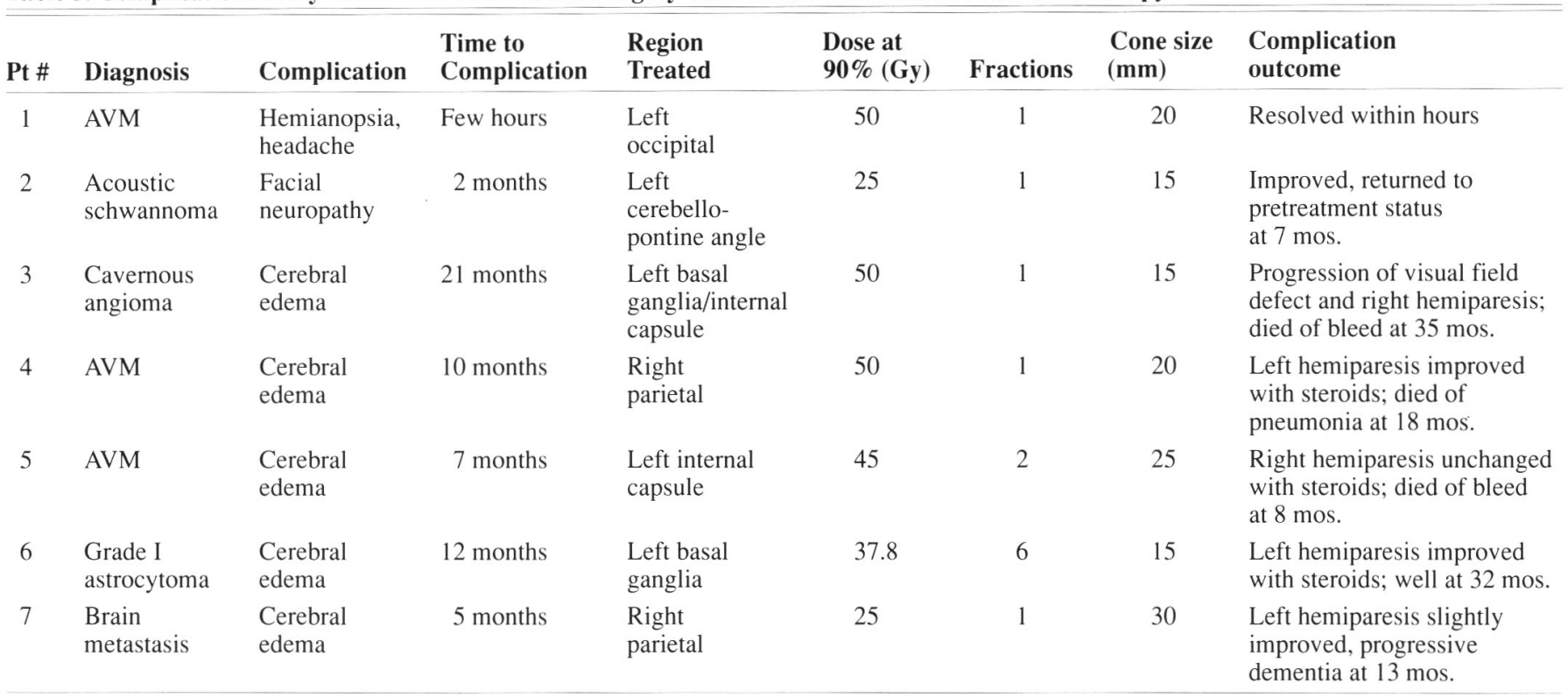

scan-determined extensive edema of the right frontoparietaltemporal region. He improved markedly with the administration of tapering doses of oral steroids. Angiogram at 12 months posttreatment showed a complete obliteration of his AVM with concurrent restoration of normal brain circulation. However, at 18 months after treatment he died of pneumonia; no autopsy was performed. Patient 5 was treated for an AVM in the left internal capsule. Seven months later, she developed right hemiparesis and extensive edema in the region of the left internal capsule on CT scan. Angiogram showed a $60 \%$ obliteration. Her symptoms failed to respond to the administration of oral steroids, and she died of a large left frontoparietal bleed eight months after radiosurgery. No autopsy was performed. Patient 6 received fractionated treatment for a grade I astrocytoma of the left lenticular nucleus. Twelve months following therapy she developed progressive left hemiparesis; a CT scan revealed the presence of extensive edema in the region of the left basal ganglia. Her symptoms improved markedly with oral steroids, and, at 26 months after treatment, she had minimal motor deficits, with disappearance of edema and substantial reduction of tumour on CT scanning.

Patient 7 was treated for palliation of a lesion in the right parietal lobe metastatic from a carcinoma of the lung. The lesion recurred five months following conventional whole brain irradiation to a midplane dose of $30 \mathrm{~Gy}$ in ten fractions given over a two week period. Five months after radiosurgery, she developed progression of her left hemiparesis, which improved modestly with administration of oral steroids. At that time, CT scan of the head revealed disappearance of the metastatic lesion, with marked edema of the right parietal lobe. At seven months following radiosurgery, in addition to the edema, an area of linear contrast enhancement was seen in the treated area. A subsequent CT scan at 11 months after therapy revealed persistent edema with near complete disappearance of enhancement. Figure 3 shows the series of pre-treatment and post-treatment CT scans. The patient remains hospitalized with hemiparesis and a progressive globally dementing illness, for which extensive investigation has failed to reveal a cause, and which may be related to her previous whole brain irradiation.

Table 4 gives the details of statistical comparisons for various treatment and patient-related parameters. There was no significant difference in the incidence of intermediate or late brain parenchymal complications between the patients that were treated with a single treatment and those that received fractionated therapy, or between those who had received previous irradiation and those who had not. There was no significant difference between patients with and without brain parenchymal complications with respect to collimator diameter, total dose administered to the $90 \%$ isodose surface, the type of lesion, or the anatomical region that was treated for either the single or the fractionated treatment groups.

\section{Discussion}

Significant acute effects of radiosurgery, i.e., those occurring within days to weeks of treatment, appear to be uncommon. Kjellberg et al. ${ }^{22}$ reported that headache, elevated temperature (with treatment of diencephalic AVMs) and increased risk of seizures occurred in a few patients treated with protons. Loeffler et al. ${ }^{23}$ reported transient aphasia beginning 12 hours post-treatment in one patient who received radiosurgical therapy using a linac-based technique. Alexander et al. ${ }^{29}$ correlated the incidence of acute nausea in linac radiosurgery patients with the dose that had been administered to the vomiting center, located in the floor of the fourth ventricle. In our series, only one patient treated with dynamic rotational radiosurgery developed transient early adverse effects.

In Stockholm ${ }^{9} 18 \%$ of patients treated with the gamma unit for acoustic schwannoma developed trigeminal neuropathy, almost always involving the sensory division, and $15 \%$ developed facial neuropathy. Five percent of patients developed symptomatic peritumoural edema 6 to 12 months following radiosurgical treatment. In Pittsburgh ${ }^{30}$ the incidence of trigeminal 


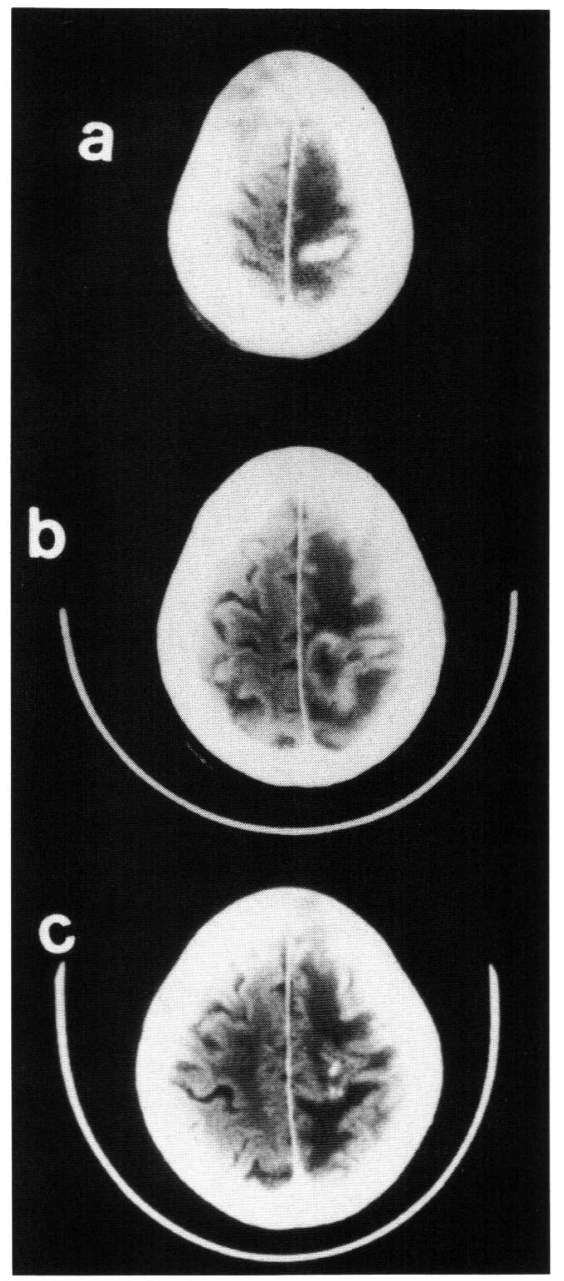

Figare 3-CT scanning in the transverse plane with administration of contrast material in Patient 7 a) before treatment, b) at seven months after treatment, and c) at 11 months after treatment. Note the presence in the right parietal lobe of the brain metastasis that was treated with radiosurgery, the development of linear enhancement and vasogenic edema at seven months, and the persistence of edema at 11 months.

and facial neuropathies at one year following therapy with the gamma unit was $37 \%$ and $33 \%$, respectively. Although the higher than expected incidence of complications led to a reduction in the minimum target dose, on subsequent analysis no significant relationship could be detected between treatment dose or minimal tumour isodose and the incidence of trigeminal or facial nerve dysfunction. In our series, one patient developed a transient facial neuropathy. The early Stockholm experience confirmed that gamma unit radiosurgery with doses $180 \mathrm{~Gy}$ or higher produced small, well demarcated areas of brain necrosis (gamma lesions) when it was administered to treat functional disorders. ${ }^{3.31-33}$ Wennerstrand and Ungerstedt ${ }^{33}$ sectioned nine brains of patients who had received 180 to $250 \mathrm{~Gy}$ for pain syndromes and found necrosis of brain tissue as early as three weeks following treatment. Leksell et al. ${ }^{32}$ found that these lesions could be seen on MRI as early as 24 hours post-treatment. Arndt et al. ${ }^{31}$ examined gamma lesions in animal brains and divided pathological changes into stages: the first or necrotic stage, at three to four weeks after treatment; the second or resorption stage, with chronic inflammatory cell infiltrate at up to one year following therapy; and the third or late stage, with prominent glial formation at one year and beyond. Histological sections of brain have revealed well circumscribed areas of radiation necrosis in patients receiving much less than 180 Gy using protons ${ }^{34}$ and gamma unit radiosurgery. ${ }^{35}$ The etiopathogenesis of the radiosurgery-induced imaging changes and the adverse reactions are not clearly understood. Blood-brain-barrier breakdown with subsequent edema and/or radiation injury of the adjacent brain tissue resulting in edema, ischemia or reactive astrocytosis have all been considered as possible mechanisms in the development of late complications. ${ }^{36,37}$

With helium ion radiosurgery, Steinberger et al. ${ }^{38}$ reported the development of symptomatic. white matter change or vasculopathy in 17 of 86 patients (20\%), three to 33 months after radiosurgical treatment of AVMs. In 20 other patients who were asymptomatic, evidence of white matter change was also seen on follow-up MRI or CT scanning. Steiner et al. ${ }^{8}$ reported an overall incidence of $7 / 300(2.3 \%)$ of delayed brain necrosis three to 11 months following treatment of AVMs with the gamma unit. Coffey et al. ${ }^{21}$ reported complications in general in $6 / 213(2.8 \%)$ of their own gamma unit patients. Kjellberg et al. ${ }^{22}$ reported an incidence of complications of $10 / 709(1.4 \%)$ in patients with AVMs treated with protons. In the series of Loeffler et al., ${ }^{23} 2 / 44$ patients (4.5\%) developed delayed radiation necrosis one at six and the other at 28 months following treatment with a linac-based technique. In our series, overall complications developed in seven of 112 patients (6.3\%).

As important as they are in conventional external beam irradiation, dose and volume considerations are likely also to be important in the incidence of late adverse effects of radiosurgery. Steiner et al.$^{39}$ reviewed gamma unit radiosurgical data and found more frequent complications at higher doses, suggesting a possible threshold prescribed dose of $20 \mathrm{~Gy}$ with an $8 \mathrm{~mm}$ or $14 \mathrm{~mm}$ collimator. Nedzi et al. ${ }^{40}$ found that an increased incidence of complications in patients with intracranial tumours treated with linac-based radiosurgery was associated with maximum tumour doses greater than 25 Gy and normal tissue doses greater than $23 \mathrm{~Gy}$, as well as with treated tumour volume greater than $10 \mathrm{~cm}^{3}$. Steinberger et al. ${ }^{38}$ found that clinical complications were more frequent with prescribed doses greater than $18.5 \mathrm{~Gy}$ or with volumes of treated tissue greater than $13 \mathrm{~cm}^{3}$. Kjellberg ${ }^{41}$ established isoeffect curves for proton beams, plotting $1 \%$ and $99 \%$ brain necrosis incidence lines with respect to dose and beam diameter. Flickinger ${ }^{42}$ identified the difficulties in applying the proton beam curves to radiosurgery with photon beams and introduced the integrated logistic model for the prediction of complication rates with respect to dose and treatment volume. Using this model, Flickinger et al. ${ }^{43}$ later generated dose-volume isoeffect curves for linac-based and gamma unit radiosurgery and found results for the two photon beam techniques similar. Flickinger and Steiner ${ }^{44}$ modified the formula for response to dose higher than $130 \mathrm{~Gy}$, using data from the production of gamma lesions. It has not been established yet whether any of these curves actually predicts the incidence of complications, although in some centers the curves may be used to select a dose that is appropriate for a particular treatment volume. ${ }^{23}$ 
Table 4. Comparison of Patients With and Without Brain Parenchymal Complications

\begin{tabular}{lcc} 
Comparison & $\chi^{2}$ & P Value \\
Single vs. fractionated & 0.545 & $\mathrm{p}>0.3$ \\
Previous irradiation & 0.210 & $\mathrm{p}>0.8$ \\
$\quad$ Total dose & & \\
$\quad$ Single treatments & 0.553 & $\mathrm{p}>0.7$ \\
$\quad$ Fractionated treatments & 0.241 & $\mathrm{p}>0.8$ \\
Collimator diameter & & \\
$\quad$ Single treatments & 4.205 & $\mathrm{p}=0.15$ \\
$\quad$ Fractionated treatments & 0.652 & $\mathrm{p}>0.7$ \\
Anatomical region & & \\
$\quad$ Single + Fractionated & 2.772 & $\mathrm{p}>0.2$ \\
$\quad$ Single treatments & 0.666 & $\mathrm{p}>0.7$ \\
$\quad$ Fractionated treatments & 2.802 & $\mathrm{p}>0.2$ \\
Lesion type & & \\
$\quad$ Single + Fractionated & 0.170 & $\mathrm{p}>0.5$ \\
$\quad$ Single treatments & 0.034 & $\mathrm{p}>0.8$ \\
$\quad$ Fractionated treatments & 0.536 & $\mathrm{p}>0.3$ \\
\hline
\end{tabular}

Other factors may influence the risk of significant late effects. Nedzi et al. ${ }^{40}$ found that tumour dose inhomogeneity and the number of isocenters used in linac-based radiosurgery correlated with the incidence of adverse late effects in patients treated for intracranial tumours. Kjellberg et al. ${ }^{22}$ found that they were able to reduce the incidence of complications over time by reducing the prescribed dose in patients with prior neurologic deficits, in whom injured brain may have a lower threshold for damage, and in patients with AVMs that were large or adjacent to neurologically active areas. Backlund et al. ${ }^{45}$ considered the tolerance of any portion of the optic tracts to radiosurgery to be $10 \mathrm{~Gy}$ and planned treatment of pituitary lesions accordingly. Kondziolka et al. ${ }^{46}$ chose to limit the dose to the optic chiasm to $8 \mathrm{~Gy}$, and, following the observation that the incidence of new neuropathies after the treatment of clival meningiomas was lower than it was with the treatment of acoustic schwannoma, ${ }^{30}$ suggested that the tolerance of some cranial nerves to radiosurgery may differ from that of others. Steinberg et al. ${ }^{38}$ found that clinical complications were more frequent in patients with lesions in the brain stem, thalamus, or basal ganglia than in those with lesions in other sites. Loeffler et al. ${ }^{23}$ were not prepared to use radiosurgery to treat lesions in previously irradiated critical regions of the brain. Nevertheless, there are no data on the tolerance of such structures as brain stem and optic nerve to the very small volumes that are treated in radiosurgery.

Interstitial brachytherapy with high-activity removable iodine-125 implants has been used as a boost to external beam irradiation in patients with malignant gliomas. Like radiosurgery, interstitial implant can deliver a large dose to the target volume while sparing adjacent normal tissue. Interstitial implant is well tolerated and appears to prolong survival. However, recent reports ${ }^{47.48}$ show that about $40 \%$ of the patients treated with this technique will require a reoperation for removal of radiation-induced necrosis, tumour progression, or a combination of both. Radiation-induced necrosis was indistinguishable from tumour progression on imaging studies. The clinical and radiologic findings on late complications following interstitial implants are similar to those seen following radiosurgery.

At McGill University intermediate or late adverse brain parenchymal effects in the form of cerebral edema, of linac radiosurgery and fractionated stereotactic radiotherapy were seen in five of 112 patients $(4.5 \%)$. In three of these patients they were severe, causing significant morbidity. No relationship was found between the incidence of edema and dose, fractionation, collimator diameter, region of the brain or lesion type treated, or history of previous irradiation. This negative finding may be attributed to the very small numbers of patients who developed significant complications, precluding a more sophisticated statistical analysis.

In general, both radiosurgery and fractionated stereotactic radiotherapy appear to be well tolerated by the vast majority of patients, although the procedures are not without risk. The consideration of the lesion type, any previous irradiation, volume, total dose and fractionation, dose homogeneity, and the presence of adjacent critical structures are likely to be important in planning therapy with any radiosurgical technique. However, extensive clinical experience will be required to define optimal prescriptions of dose related to volume, the potential role of fractionated treatment using stereotactic techniques, and the tolerance to radiosurgery of brain stem, optic nerve, and other critical structures, so that the incidence of significant toxicity may be further minimized. We continue to accrue patients to our program using the same dose prescription-target volume parameters described in this paper and hopefully with a sufficiently large patient population, some of the unsolved issues related to delayed complications may be clarified in the future.

Based on our 6 year experience with radiosurgery and fractionated stereotactic radiotherapy, we currently reserve radiosurgery for treatment of AVMs, metastatic brain tumours and acoustic schwannomas, while for the treatment of the selected group of patients with well-circumscribed, unresectable, primary brain tumours we use fractionated stereotactic radiotherapy.

\section{ACKNOWLEDGEMENTS}

This work was supported in part by research grant MT-10830 from the Medical Research Council of Canada.

\section{REFERENCES}

1. Leksell L. A stereotaxic method and radiosurgery of the brain. Acta Chir Scand 1951; 102: 316-319.

2. Leksell L, Larsson B, Andersson B, et al. Lesions in the depth of the brain produced by a beam of high energy protons. Acta Radiol 1960; 54: 251-264.

3. Leksell L. Cerebral radiosurgery: I Gammathalamotomy in two cases of intractable pain. Acta Chir Scand 1968; 134: 585-595.

4. Leksell DG. Stereotactic radiosurgery: present status and future trends. Neurol Res 1987; 9:60-68.

5. Kjellberg RN, Preston WM. The use of the Bragg peak of a proton beam for intracerebral lesions. Proceedings of the Second International Congress of Neurological Surgery, Washington, D.C. Excerpt Med 1961; 36: E103.

6. Tobias CA, Lawrence JH, Born JL, et al. Pituitary irradiation with high-energy proton beams: a preliminary report. Cancer Res 1958; 18: 121-134.

7. Kjellberg RN, Hanamura T, Davis KR, Lyons SL, Adams RD. Bragg peak proton beam therapy for arteriovenous malformations of the brain. N Engl J Med 1983; 309: 269-274.

8. Steiner L. Stereotactic radiosurgery with the Cobalt-60 gamma unit in the surgical treatment of intracranial tumours and arteriovenous malformations. In: Schmidek HH, Sweet WH, eds. Operative Neurosurgical Techniques - Indications, Methods, and Results. Philadelphia: WB Saunders, 1988; 515-529. 
9. Noren G, Arndt J, Hindmarsh T. Stereotactic radiosurgical treatment of acoustic neurinomas. In: Lunsford LD, ed. Modern Stereotactic Neurosurgery. Boston: Martinus Nijhoff, 1988; 481-489.

10. Lunsford LD, Flickinger J, Coffey RJ: Stereotactic gamma knife radiosurgery: initial North American experience in 207 patients. Arch Neurol 1990; 47: 169-175.

11. Walton L, Bomford CK, Ramsden D. The Sheffield Stereotactic Radiosurgery Unit: physical characteristics and principles of operation. Br J Radiol 1987; 60: 897-906.

12. Betti OO, Munari C, Rosler R. Stereotactic radiosurgery with the linear accelerator: treatment of arteriovenous malformations. Neurosurgery $1989 ; 24: 311-321$

13. Colombo F, Benedetti A, Pozza F, et al. External stereotactic irradiation by linear accelerator. Neurosurgery 1985; 16: 154-160.

14. Friedman A. Linac radiosurgery. Neurosurg Clin N Am 1990; 1: 991-1008

15. Hartmann GH, Schlegel W, Sturm V, et al. Cerebral radiation surgery using moving field irradiation at a linear accelerator facility. Int J Radiat Oncol Biol Phys 1985; 11: 1185-1192.

16. Hitchcock E, Kitchen G, Dalton E, Pope B. Stereotactic linac radiosurgery. Br J Neurosurg 1989; 3: 305-312.

17. Loeffler JS, Alexander E, Siddon RL, et al. Stereotactic radiosurgery for intracranial arteriovenous malformations using a standard linear accelerator. Int J Radiat Oncol Biol Phys 1989; 17: 672-677.

18. Podgorsak EB, Olivier A, Pla M, Lefebvre PY, Hazel J. Dynamic stereotactic radiosurgery. Int J Radiat Oncol Biol Phys 1988; 14 : 115-126.

19. Gutin PH, Wilson CB. Radiosurgery for malignant brain tumours. J Clin Onc 1990; 8: 571-573.

20. Sheline GE, Wara WM, Smith V. Therapeutic irradiation and brain injury. Int J Radiat Oncol Biol Phys 1980; 6: 1215-1228.

21. Coffey RJ, Lunsford LD. Stereotactic radiosurgery using the 201 Cobalt-60 source gamma knife. Neurosurg Clin N Am 1990; I: 933-953.

22. Kjellberg RN, Davis KR, Lyons S, Butler W, Adams RD. Bragg peak proton beam therapy for arteriovenous malformation of the brain. Clin Neurosurg 1983; 31: 248-290.

23. Loeffler JS, Siddon RL, Wen PY, Nedzi LA, Alexander E. Stereotactic radiosurgery of the brain using a standard linear accelerator: a study of early and late effects. Radiother Oncol 1990; 17: 311-321.

24. Steiner L. Radiosurgery in cerebral arteriovenous malformations. In: Flamm E, Fein J, eds. Textbook of Cerebrovascular Surgery. New York: Springer Verlag, 1986; 1161-1215.

25. Souhami L, Olivier A, Podgorsak EB, et al. Dynamic stereotactic radiosurgery in arteriovenous malformations. Preliminary treatment results. Cancer 1990; 66: 15-20.

26. Souhami L, Olivier A, Podgorsak EB, Pla M, Pike GB. Radiosurgery of cerebral arteriovenous malformations with the dynamic stereotactic irradiation. Int J Radiat Oncol Biol Phys 1990; 19: $775-782$

27. Souhami L, Olivier A, Podgorsak EB, et al. Fractionated stereotactic radiotherapy for intracranial tumours. Cancer 199I; 68: 2101-2108.

28. Clark BG, Podgorsak EB, Souhami L, et al. A halo-ring technique for fractionated stereolactic radiotherapy. $\mathrm{Br} J$ Radiol, 1993; 66 : 522-527.

29. Alexander E, Siddon RL, Loeffler JS. The acute onset of nausea and vomiting following stereotactic radiosurgery: correlation with total dose to area postrema. Surg Neurol 1989; 32:40-44.

30. Flickinger JC, Lunsford LD, Coffey RJ, et al. Radiosurgery of acoustic neurinomas. Cancer 1991; 67: 345-353.

31. Arndt J, Backlund EO, Larsson B, et al. Stereotactic irradiation of intracranial structures: physical and biological considerations. $I n$ :
Szikla G, ed. Stereotactic Cerebral Irradiation: INSERM Symposium No. 12. Amsterdam: Elsevier/North Holland Biomedical Press, 1979; 81-92.

32. Leksell L, Herner T, Leksell D, Persson B, Lindquist C. Visualization of stereotactic radiolesions by nuclear magnetic resonance. $J$ Neurol Neurosurg Psychiatry 1985; 48: 19-20.

33. Wennerstrand J, Ungerstedt U. Cerebral radiosurgery II: an anatomical study of gamma radiolesions. Acta Chir Scand 1970; 136: 133-137.

34. Nielsen SL, Kjellberg RN, Asbury AK, Koehler AM. Neuropathologic effects of proton-beam irradiation in man: l Doseresponse relationships after treatment of intracranial neoplasms. Acta Neuropathol (Berlin) 1972; 20: 348-356.

35. Thompson BG, Coffey RJ, Flickinger JC, Lunsford LD. Stereotactic radiosurgery of small intracranial tumours: neuropathological correlation in three patients. Surg Neurol 1990; 33: 96-104.

36. Flickinger JC, Lunsford LD, Kondziolka D, et al. Radiosurgery and brain tolerance: an analysis of neurodiagnostic imaging changes after gamma knife radiosurgery for arteriovenous malformations. Int J Radiat Oncol Biol Phys 1992; 23: 19-26.

37. Lunsford LD, Altschuler E, Flickinger JC, Wu A, Martinez AJ. In vivo radiobiology of stereotactic radiosurgery: a primate model. Neurosurgery 1990; 27: 373-382.

38. Steiberg GK, Fabrikant JI, Marks MP, et al. Stereotactic heavycharged particle Bragg-peak radiation for intracranial arteriovenous malformations. N Engl J Med 1990; 323: 96-101.

39. Steiner L, Greitz T, Backlund EO, et al. Radiosurgery in arteriovenous malformations of the brain: undue effects. In: Szikla G, ed. Stereotactic Cerebral Irradiation: INSERM Symposium No. 12. Amsterdam: Elsevier/North Holland Biomedical Press, 1979; 257-269.

40. Nedzi LA, Kooy H, Alexander E, Gelman RS, Loeffler JS. Variables associated with the development of complications from radiosurgery of intracranial tumours. Int J Radiat Oncol Biol Phys 1991; 21: 591-599.

41. Kjelıberg RN. Isoeffective dose parameters for brain necrosis in relation to proton radiosurgical dosimetry. In: Szikla G, ed. Stereotactic Cerebral Irradiation: INSERM Symposium No. 12. Amsterdam: Elsevier/North Holland Biomedical Press, 1979; 157-166.

42. Flickinger JC. An integrated logistic formula for prediction of complications from radiosurgery. Int J Radiat Oncol Biol Phys 1989; 17: 879-885.

43. Flickinger JC, Schell MC, Larson DA. Estimation of complications for linear accelerator with the integrated logistic formula. Int $J$ Radiat Oncol Biol Phys 1990; 19: 143-148.

44. Flickinger JC, Steiner L. Radiosurgery and the double logistic product formula. Radiother Oncol 1990; 17: 229-237.

45. Backlund EO, Bergstrand $G$, Hierton-Laurell $U$, et al. Tumour changes after single dose irradiation by stereotactic radiosurgery in "non-active" pituitary adenomas and prolactinomas. In: Szikla G, ed. Stereotactic Cerebral Irradiation: INSERM Symposium No. 12. Amsterdam: Elsevier/North Holland Biomedical Press, 1979; 199-206.

46. Kondziolka D, Lunsford LD, Coffey RJ, Flickinger JC. Stereotactic radiosurgery of meningiomas. J Neurosurg 1991: 74: 552-559.

47. Gutin PH, Prados MD, Phillips TL, et al. External irradiation followed by an interstitial high activity iodine-125 implant "boost" in the initial treatment of malignant gliomas: NCOG study 6G82-2. Int J Radiat Biol Phys 1991: 21: 601-609.

48. Scharfen CO, Sneed PK, Wara WM, et al. High activity iodine-125 interstitial implant for gliomas. Int J Radiat Oncol Biol Phys 1992; $24: 583-591$. 